\title{
Telecenters in the Development of the Smart Village Cybergogy for Multicultural Transformation
}

\author{
Jalaluddin Abdul Malek \\ Sustainable of Social, Environmental and Development \\ Centre (SEEDS) \\ Faculty of Social Sciences and Humanities \\ UKM, Bangi. \\ jbam@ukm.edu.my
}

\author{
Zurinah Tahir \\ Sustainable of Social, Environmental and Development \\ Centre (SEEDS) \\ Faculty of Social Sciences and Humanities \\ UKM, Bangi. \\ zurinahtahir@ukm.edu.my
}

\begin{abstract}
Cybergogy which is made available via telecenters in rural Malaysia has the potential to produce a knowledgeable community that is the foundation of a Smart Village (SV). By 2007, Malaysia had more than two thousand telecentres that served as vehicles for the development of SVs. The telecenters' three operational units are the Mini Rural Transformation Center (mini RTC), the 1Malaysia Internet Center and the Rural Internet Centre. Learning undertaken in rural internet centers since 2015 has emphasized the Bridging Digital Divide (BDD) Program that involves the use of the computer and the Internet. Internet Centers are paying more attention to the transformation of the culture and thinking of the rural population to achieve a hybrid economy that melds social economy with online business. The method of learning that is adopted is cybergogy, which valueadds the elements of peeragogy and synergy. The present study poses the question as to the extent cybergogy effected through the Mini RTC telecenter has brought about a multicultural transformation in a smart community (SC). This study also examines the effects of cybergogy as implemented in Malaysia, based on world views as well as on knowledge and practices adopted by rural SCs in SVs. The results are modest in terms of achievements in the SC. An explanation for this limited success is that cybergogy at telecenters has received only moderate reception
\end{abstract}

Keywords- Cybergogy; Telecenter; Smart Village; Multicultural; Transformation

\section{INTRODUCTION}

This discussion centers on critical pedagogy epistemology that encourages radical teaching [1]. The main question that arises in critical pedagogy is: Does rural education today provide space for agencies or processes that nurture creative subjectivity? Rural education serves as a platform to accelerate development for the village folk with amenities such as the telecenter, library and guidance for various activities. Rural education can be formal or informal. This discussion is closely tied to the roles of the telecenter as a global developmental platform to hasten the development of a knowledgeable rural community. In line with plans to uplift the welfare of the rural folk, increasing attention is directed towards empowering rural residents so that they need not feel left out in this age of modern technology. By enriching their knowledge, the villagers can be players who are proactive and receptive to compromise where the situation warrants it. All this makes for a rural community that is self-reliant in its development [2].

Smart Villages (SV) are villages that are equipped with comprehensive modern technological facilities such as ICT and solar technology. The components of development in SVs encompass the smart economy, smart community (SC), smart surroundings, smart grid, smart utilities and smart education [3]. The main emphasis in SV development is on inclusive development of SC in line with rural development undertaken elsewhere in the country. Among the basic facilities of SVs are telecenters that may either be wired or wireless.

Cybergogy is a form of self-learning that takes place via the Internet under professional guidance. Members of the SV community adopt such an approach to self-selected learning that they see as beneficial to themselves, to their families and to the community as a whole. Cybergogy is well suited to rural educational programs as it does not restrict the participant to a specific time, space, place or grouping. Such an approach to imparting knowledge can help to strengthen the foundation of $\mathrm{SV}$, where there is easy access to the Internet at telecenters. Cybergogy also serves to transfer know-how to the rural population from the political/administrative, economic, demographic, socio-cultural, infrastructural/info-structural, innovative, technological, educational, legal and environmental standpoints (PEDSITELE).

Telecenters are 'one-stop centers' that offer facilities for ICT and the Internet, functioning as centers for the dissemination of knowledge, guidance, information and data, besides providing an electronic network for the rural community. Such centers contribute to the development of SVs, especially in specific areas of the socio-economy, sociopolitics and socio-culture. Telecenters go by various names in different places. They may be referred to as Mini Rural Transformation Centers (Mini RTCs), 1Malaysia Internet Centers, Public Access Internet Centers, Village Knowledge Centers, Community Technology Centers, Community Multimedia Centers, Community Telecenters, or Community Service Centers [4].

Multicultural transformation refers to the change from production economy (P-economy) to knowledge economy (Keconomy). The latter encompasses the system of utilization, production and management of intellectual and social capital. 
The K-economy covers a large part of multicultural economic activities of developed countries, encompassing both social and psychological capital. Considerable economic value is derived from intangible assets that include the aspects of growth and development deemed endogenous, neoendogenous and neo-exogenous. The multicultural transformation from P-Economy to K-economy alters the mindset of people, and hence has an important bearing on human capital and social capital from the viewpoint of politics and administration, economy, demography, socio-cultural aspects, infrastructure and infostructure, technological adaptation and innovation, educational development, legal issues and their enforcement, and the environment (PEDSITELE) [5].

\section{A. Malaysian Smart Village (SV)}

The Smart Village Vision for Malaysia seeks to link the rural community to the mainstream socio-economy, socioculture and socio-politics through the use of technology. Four objectives have been sighted for this endeavor: i. To enhance rural productivity, ii. To raise IT literacy as an enabler of advancement, iii. To raise the rural standard of living through socio-economic, socio-cultural and socio-political activities, iv. To achieve socio-economic status that is inclusive, based on the realignment of socio-economic, socio-cultural and socio-political perspectives to shape a community that acquires knowledge via electronic networks.
The Malaysian Smart Village places into focus the need to unify and list the rural development programs that remain in the purview of various ministries. The next priority is to collate, co-ordinate and streamline the various projects to achieve maximum impact, and to render them inclusive and sustainable. The third consideration is to rid the system of unnecessary intermediaries so that the rural folk can directly involve themselves in building up their socio-economic, sociocultural and socio-political capabilities.

The strategy to realizing the Malaysian Smart Village involves various steps and mechanisms, beginning with the adoption of an economy-driven approach in order to set the project within a viable framework. The next important consideration is to put the required infrastructure in place so that supporting services for socio-economic activities in the rural areas can proceed. The third consideration is the bringing together of all interested parties to undertake an integrated program that is resilient and sustainable.

The Malaysian Smart Village requires the active participation of interested sectors so that their joint efforts would spearhead the necessary development. At the top of this list is the private commercial sector, the main industry player that provides the technology or the supporting infrastructure. The next important participant is the government, or specifically the Ministry of Rural Development which is responsible for the development of the Malaysian Smart Village (Figure 1).

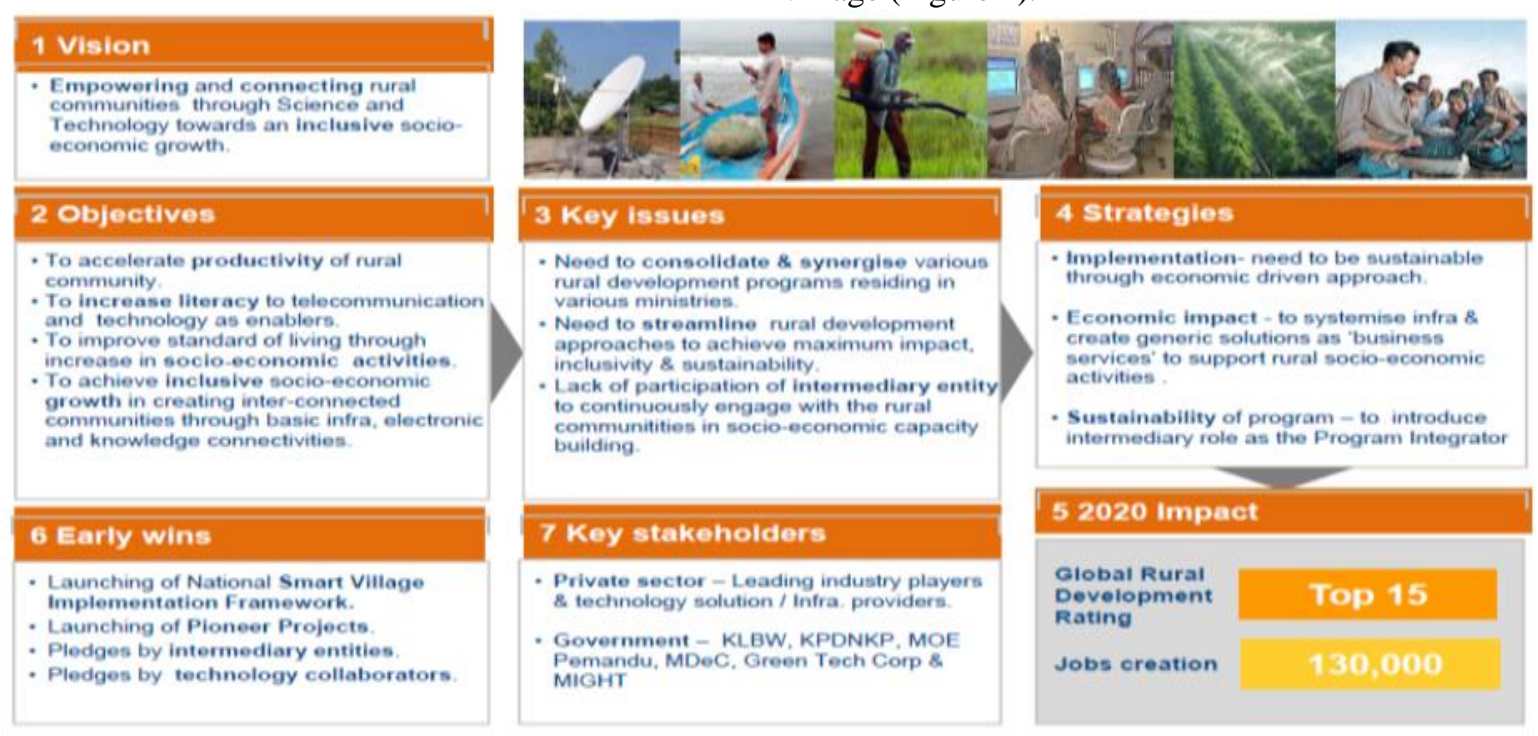

Fig 1. Malaysian Smart Village development

Source: MiGHT9 [6], JPM 2011 [7]

Malaysian Smart Villages emphasize the development of the socio-economic sector through a multicultural transformation that places knowledge as a requisite. Rural knowledge centers aim to offer know-how and opportunities in banking and finance, education, work and industrialization. An amalgamation of manpower resources, transportation, water supply and ICT would be required to build the Smart Village (SV) (Figure 2). With the setting up of village knowledge centers such as telecenters, farmers would be able to access relevant information from the Internet on topics such as soil remediation, seeds and propagules, water management, post-harvest management and crop productivity. Fishermen can have access to meteorological data, information on catch boundaries, fish availability, storage systems, marketing, boat and net repair through the adoption of ICT. Livestock breeders are also able to use ICT to keep themselves updated on animal feed management, alternative ways for waste management as well as animal disease prevention and management. Rural folk running cottage industries can familiarize themselves with potential markets and marketing strategies, supply chain networks, current rules and regulations, available incentives, 
new and improved processes, and best practices in the industry

(Figure 2)
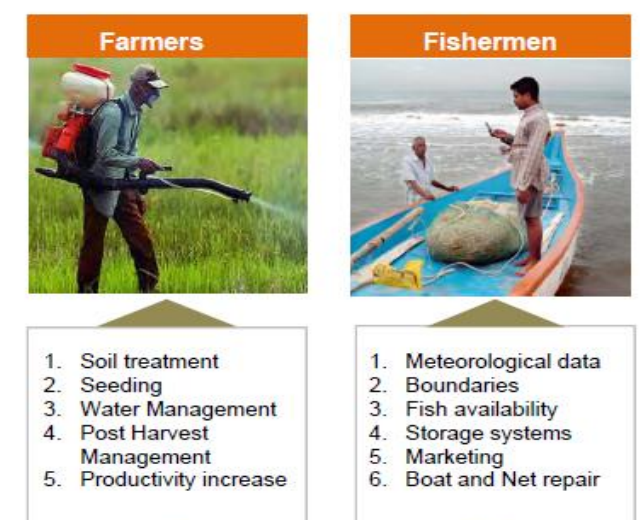

Meteorological data Boundaries Fish availability

Storage systems

5. Marketing

6. Boat and Net repair

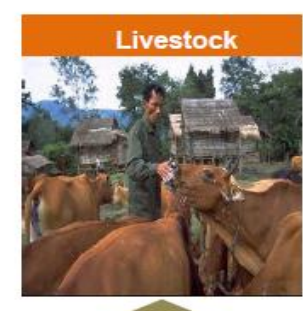

Food management

2. Waste management and alternatives

. Outbreak prevention

management
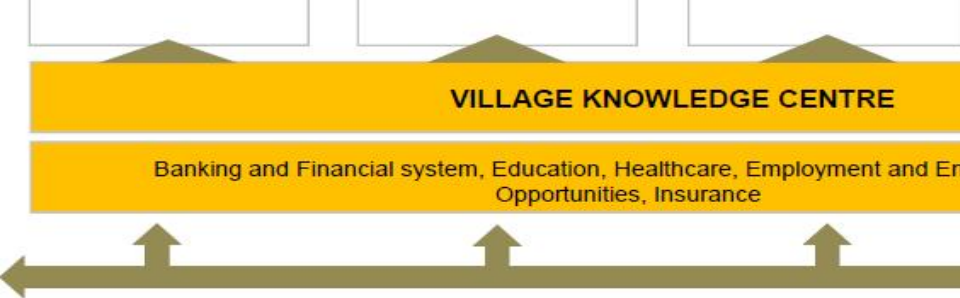

VILLAGE KNOWLEDGE CENTRE

Connectivity Enablers: Power/Energy, Road, Transport, Water, Electronics/ICT,

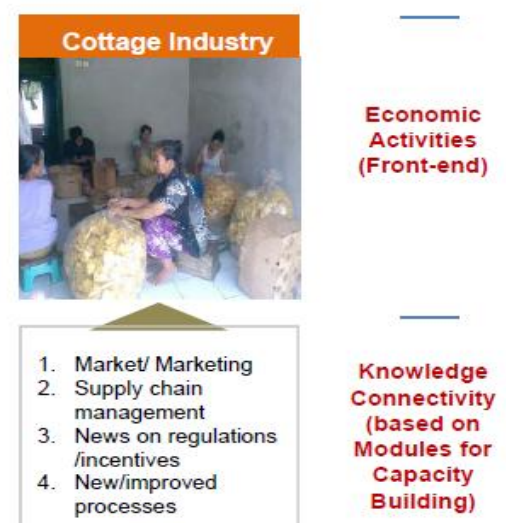

Connectivity

Hubs

(Back-end)

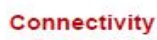

Enablers

Fig 2. Aspects of Malaysian Smart Village development Source: MiGHT [6], JPM 2011 [7]

The Rural Transformation Centers (RTC) in Malaysia is a facility set up in mid-2011 to service villages within a radius of $100 \mathrm{~km}$. It is involved in carrying out high value-added activities that contribute to building the economy and raising the living standards of the rural population. RTCs provide cyber-education to facilitate rural residents' involvement in digital commerce. Online commerce between rural and urban regions of the country is made possible through an electronic network of RTCs and mini RTCs. On top of this, there is also communication between RTCs and the Urban Transformation Centers (UTCs) and mini UTCs (Figure 3). Besides these functions, RTCs also serve rural residents as government onestop centers and marketing centers for agricultural produce, animal produce, fisheries, and products from small and medium-scale industries

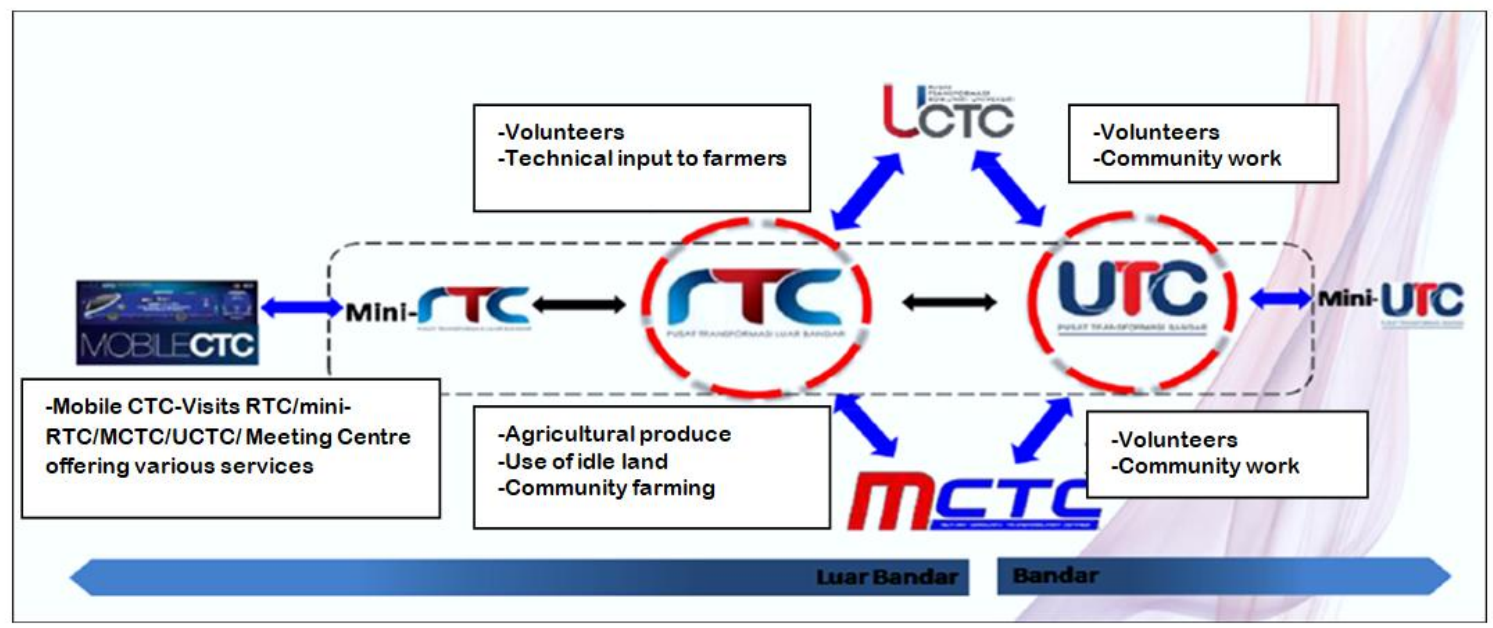

Fig 3. Mini RTC, RTC, UTC and Mini UTC Source: JPM 2013 [7]

Through the establishment of RTCs, the locals are able to carry out activities such as the sale of agricultural produce online at competitive prices while acquiring expertise in online commerce. Mini RTCs are essentially branch RTCs that act as governmental agencies to supply online information and services to people living in the distal rural areas. 


\section{B. Rural Education Issues Of Smart Villages (Sv)}

Online education available to the SV community holds the promise of building a rural society that explores and seeks information, and that is able to apply the acquired know-how. Residents can also innovate or adopt innovations to improve their livelihood. The hopes and aspirations of the rural community can be met when SV places due emphasis on empowering the rural population to achieve a smart society (SC) [3].

The formation of successful SCs is dependent on telecenter facilities made available to SVs. Such telecenters can be set up by the government, the commercial sector, NGOs or even by individuals. Telecenters run on a for-profit basis are known as cybercafes. Among the educational programs available at telecenters initiated by the government (i.e. Mini RTCs and 1Malaysia Internet Centers) are those that pertain to e-government, counseling, e-commerce, innovation and creativity promotions, printing and publication, processing and packaging rural products, in addition to guidance for emarketing e.g. e-payment and e-banking. All these efforts are ultimately aimed at turning villagers into residents of a SC capable of functioning independently. An SC that achieves an adequate level of capability essentially contributes to development of PEDSITELE [8].

The foregoing notwithstanding, the question arises as to the extent cybergogy can achieve knowledge specific to their requirements? To what extent can a villager benefit from a rural developmental program? To what extent can a rural resident use interpersonal and intrapersonal communication intelligence to build up PEDSITELE? To what extent can the development of an SC through cybergogy in a telecenter bring about a society that is active, proactive, receptive to learning, innovative and able to sustain whatever progress that has been achieved?

Cybergogy methodology has been touted as a step forward in the quest to achieve the objectives of the SC so that rural folk can truly enjoy the benefits of living in an SV. Cybergogy does not focus only on taxonomic and human abilities, but it also promotes transformative education towards SC to expose rural residents to world commerce, knowledge and best practices. This means that the SC will be a community that can contribute freely to PEDSITELE. In this regard, cybergogy uses a multimedia learning approach involving audio and visual aids such as the computer, video displays and other ICT tools. Multimedia-based learning at telecenters emphasizes the principles that have made it so successful as an approach to teaching and learning.

SVs provide valuable feedback to the SC community in its effort to realize its goals. Nevertheless, the key to success in cybergogy lies in telecenters that are equipped with extensive ICT facilities, strong support services, and a local champion (a role model) in building a strong $\mathrm{SC}$. In this connection, the most important success factor for residents of an SV is the determination to improve their livelihood through online education and be determined to transform their neighborhood into an SC. Only then would the development of an SC contribute meaningfully to the development of the SV.

\section{Smart Village And Cybergogy Indicators}

On the matter of inclusive education, several educational approaches have been attempted, their choice depending on the type, requirement, technology, and benefit. Various educational systems had been implemented in the past, even before the industrial and political revolutions in Europe. The Islamic civilization is among the early proponents of education. For the purpose of this discussion, changes in approaches to education are looked at as interlinked contemporary revolutionary developments, many of which are the effects of what some scholars regard as the Fourth Industrial Revolution. The development of new methods in education that are detached from earlier concepts of education (pedagogy) value-adds to the existing approach; it is more suited to a society that is immersed in a process of continuous learning so that learners are updated with the latest news and findings.

Among its objectives, cybergogy is aimed at bringing about social change in the rural sector. Through the telecenter, for example, a rural resident who is adept at ICT could get in touch with another individual, or with a particular service or a business online via social networking is an application, whereas all the other networks described refer to hardware infrastructure, local area network, metropolitan network or global network (macro system, regional area network and wide area network that includes the internet). This means that the cyber-socio-ecological environment can enable individuals residing in rural locations to be acquainted with skills in entrepreneurship and in other branches of knowledge online at the telecenters. Such learning processes, cybergogy, can take place with or without online guidance (Figure 4). 


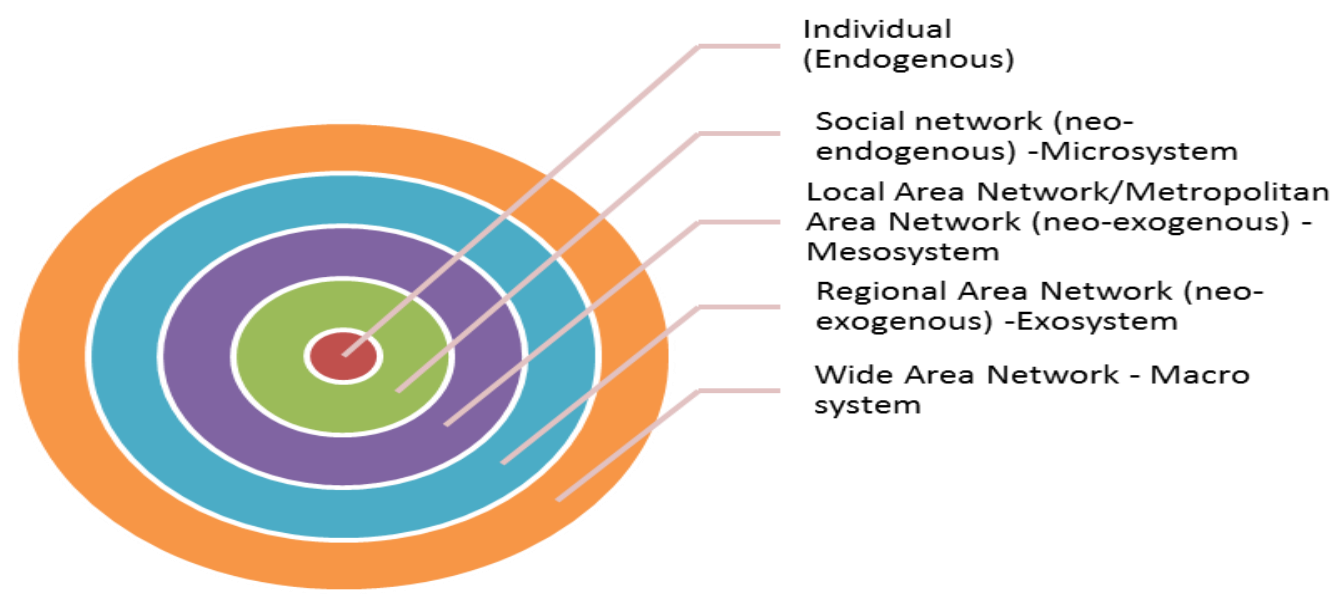

Fig 4. Cyber socio Ecological Framework

Source: Adaptation from Bronfenbrenner [9], Green at al [10], Jalaluddin \& Zurinah 2016 [8]

Cybergogy is a method of teaching in this era of information revolution. This is also the era of globalization following the rise of ICT, where the concept of a world without borders is embraced by many, where there is unlimited space, freedom from the constraints of culture and belief, and regardless of national boundaries [11]. The use of ICT has spawned a concept of teaching and learning where cybergogy, pedagogy, andragogy and peergogy are tied together through the medium of ICT [4]. Cybergogy places much emphasis on helping adults and the youth learn in a virtual environment where the virtual interface is used in processing the cognitive, emotive and social factors (Figure $5)$.

The cybergogy model is recognized as an innovative model for instruction via the use of ICT and cyberspace access available at telecenters, cybercafes and other computer centers [11] [12]. The cybergogy approach encourages learners, both young and old, to make use of the computer and internet to acquire modules, information, reports and all types of reference materials that can aid implementation of PEDSITELE. While the outcome of cybergogy is unpredictable, it can be very successful if the rural folk are made aware of its benefits. With the advent of cybergogy, developers in rural areas are now conscious of the fact that neo-endogenous and exogenous elements of development are gaining importance in the rapid pace of rural development, taking cognizance of human capital and social capital available to be tapped (Figures 2 and 3)

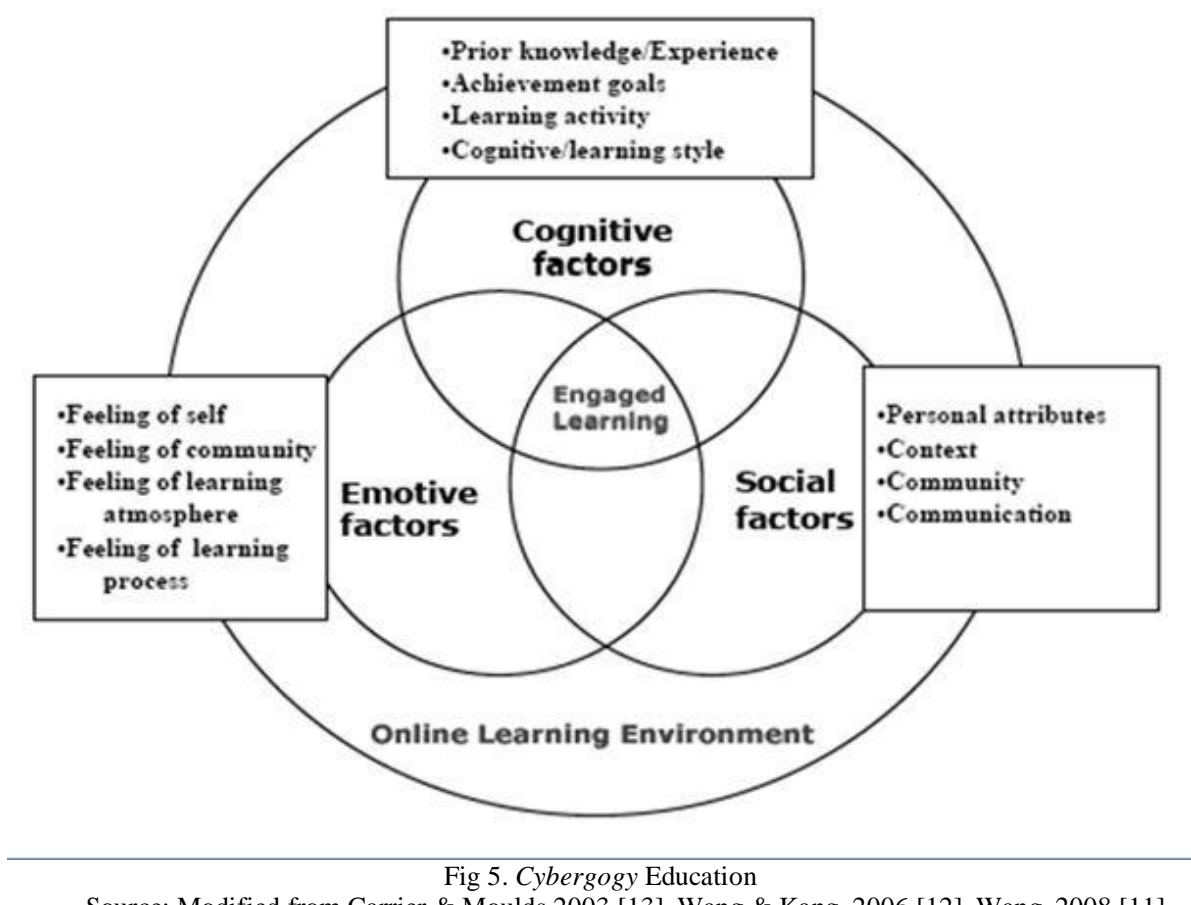

Source: Modified from Carrier \& Moulds 2003 [13], Wang \& Kang 2006 [12], Wang 2008 [11] 
Cybergogy is a system of self-learning that stems from the Fourth Industrial Revolution. Nevertheless, cybergogy is not only driven by the rise of ICT, but also by the perseverance of the rural folk to seize the opportunity to improve their livelihood through the acquisition of more knowledge and as well as to avail themselves of social networking. The roots of cybergogy can be traced to Stewart Hase and Chris Kenyon in Australia who promulgated selfdetermined learning [14]. Cybergogy value-adds to pedagogy, andragogy and synergogy. Cybergogy places much emphasis on the way of learning to create opportunities for advancement where the learner determines his own path and pace of advancement [15]. Learner initiative is a requisite to master both formal and informal learning. Unlike andragogy which tends to be highly structured, cybergogy combines the various contexts of learning, whether they are structurally formal or are introduced by human agencies or influenced by the cultural environment [14] [16].

The principles underlying cybergogy are structured to raise the capability of the people for endogenous and neo endogenous growth by placing priority on a dynamic fusion of co-operation, networking and cultural sensitivity in the development of the SV. Such a society that is being transformed requires a reinvention of innovation among participants who focus on exploiting new-found opportunities in the digital realm. It follows that the development of the SV has to be founded on resilient and competitive human capital above all else in order to secure sustainable success. The basic principles of neo-exogenous growth will inevitably be affected by the willingness for collective co-operation to take advantage of opportunities for progress and development offered by 'Blue Ocean Strategies' in innovative information and communication technology. Cybergogy education at the telecenter is founded on three major methodologies, namely:

i. The cognitive presence method involves a selfdetermined ownership of learning; it is generic learning and knowledge gathering in a meaningful discourse so as to learn from the success of others in specific fields.

ii. The emotive presence method where the learner yearns to gather knowledge in tranquil or familiar surroundings. He is affected emotionally and spiritually while seeking to advance himself and the community.

iii. The social presence method requires the learner to participate in activities that lead to a sharing of knowledge and experiences to enhance social factors and social capital. Such a method places emphasis on good communication and empathy for others, as well as a desire for personal and community wellbeing.

Cybergogy conducted at telecenters is aimed at molding an independent rural community to participate in the development of PEDSITELE, including various aspects of technological innovation. The rural population is not merely receiving development, but is also instrumental in participating pro-actively in consensus-building. Thus, they contribute to the building of the SV and become members of the SC responsible for planning for their own future in the context of rural development. In the longer term, cybergogy would produce villagers who can be viewed as role models worthy of emulation. Such individuals would be secure in their ability to apply or generate new knowledge.

Cybergogy has the potential to fashion new creative work and innovative procedures while making the best use of the rural folk's personal and inter-personal intelligence. The rural resident would be able to understand and analyze new concepts and come up with his own creative and innovative approaches based on his experience, thus contributing to new knowledge. In conclusion, cybergogy is essentially selflearning that enables erstwhile outsiders to receive training in problem-solving from a heuristic perspective while applying meta-cognitive understanding, creativity, innovation, and collaboration [13].

Although differences exist between pedagogy and andragogy on the one hand, and cybergogy on the other, success in all cases hinge on both the instructor and the learner. The rural community is not homogenous, but comprises different sectors that have different levels of achievements and abilities. Hence, while everyone can benefit from cybergogy, the specific benefits that can be grasped would vary with the individual depending on his ability to receive the teaching provided online. Telecenters are used by various sectors of the population, be they adults, males and females, young and old. In rural Malaysia, a large proportion of the rural population comprise low income and medium-low income groups. Hence, to raise the level of knowledge and ICT competency of the rural community who have access to a telecenter, it is necessary to have different modules that cater to various levels of ICT competency, i.e. those who are beginners, fairly knowledgeable, and those who have achieved a high degree of competency. The trainer, counselor or facilitator must therefore group interested learners according to their level of competency to bring create a successful SC [12] [11].

While the rural community is poised to receive cybergogy as a key thrust in the rural transformation program, its successful implementation requires human capital and proactive social capital. The Rural Transformation Program in Malaysia aims to produce rural communities that will not be completely dependent on the government for improving their livelihood. According to the National Blue Ocean Strategy (NBOS), the Rural Transformation Center (RTC) and the Mini RTC are the main premises for the implementation of cyber instruction to create knowledgeable SCs. Such a move is not only for the purpose of creating high-income households, but also to develop the community as a whole

\section{The Impact Of Cybergogy On The SMart Village Through The RTC Program At Ketengah}

The present study examined the impact of cybergogy on a Smart Village under the auspices of the Terengganu Tengah (KETENGAH) governmental scheme. Here, the telecenter not only facilitates online access to all kinds of information but also provides opportunities for networking and exchanging ideas with other interested individuals. The SV in KETENGAH also focused on developmental programs in 
various parts of the region and its countryside. KETENGAH has been in operation since 1973 (Map 1). Its main focus is to hasten the development of the rural folk in the area under its purview so that the targeted region can become a society that is modern, prosperous and progressive in their socio-economic dealings. Among the facilities at KETENGAH is the Terengganu RTC complex that functions as an integrated service center, bringing together several governmental agencies under the National Blue Ocean Strategy. It encompasses nine initiatives, namely skills training, 1Malaysia information kiosk, high-value farming, agricultural food product processing, agricultural product supply chain management, university collaboration, 1Malaysia health service, fund management facility, and agro-tourism.

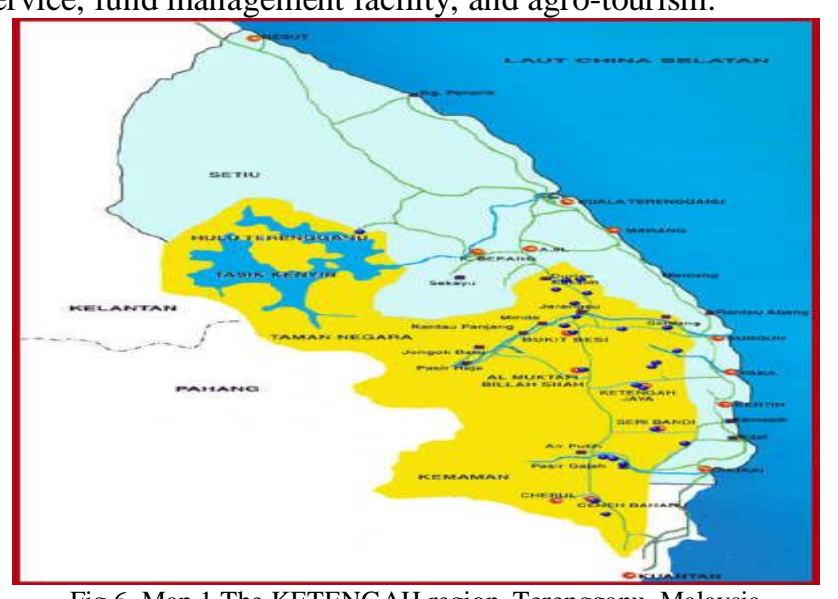

Fig 6. Map 1 The KETENGAH region, Terengganu, Malaysia Source: KETENGAH

One of the RTC programs is aimed at raising computer literacy and Internet use among the rural residents. Other than guidance from experts and facilitators, the rural folk also learn to source information from the Internet and social media using the ICT facilities of the village Mini RTCs which are linked electronically to the Terengganu RTC located in Bandar alMuktafibillah Shah. The aim of this facility is to enable rural residents to involve themselves in the K-economy by participating in e-business. Hence, it is important to investigate the extent to which cybergogy has been effective in improving the competency of rural residents' participation in the K-economy

\section{METHOD}

A study was undertaken in two villages in the KETENGAH area, namely Kampung Jerangau and Kampung Pasir Gajah. The study was quantitative, with data collected from the heads of households, as well as women and youth. The total number of residents from the two villages was 3,384. From this, 562 respondents were selected as a representative sample, giving a confidence level of $90 \%$ with a standard deviation of $10 \%$. This study placed particular emphasis on the neo-endogenous and neo-exogenous scopes of development. The neo-endogenous scope of development includes human capital and social capital, whereas the neoexogenous scope of development covers inclusiveness and achievement with respect to available ICT infrastructure facilities and the transfer of knowledge and technology

\section{RESULT AND DISCUSSION}

Of the 562 persons selected for the study, only $43.1 \%$ possessed competencies in areas like ICT skills, crafts, agriculture and commerce. Such skills placed them at an advantage when it came to improving their socio-economic status. With the remaining $56.9 \%$ of the respondents lacking such ability, the human capital in this group which had not been exposed to ICT previously can be said to be low from the neo-endogenous viewpoint. From the neo-exogenous stance, a digital divide in the community was evident since $49.8 \%$ did not own a personal computer. Of the $50.2 \%$ of the respondents who did own a personal computer, only $32.6 \%$ had Internet connections. With regard to smart phones, $39.5 \%$ did not own one. Of the $60.5 \%$ respondents who owned a smart phone, only $18.3 \%$ were linked to the Internet.

The program to bridge the digital divide at the RTC and mini RTC by introducing ICT and exposure to global commerce gradually changed the outlook of residents in Kampung Jerangau and Kampung Pasir Gajah. The implementation of cybergogy resulted in residents taking a more multicultural stance. Many considered themselves being involved in the $\mathrm{K}$ - economy. Table 1 shows the competency of rural residents with regard to various ICT-related activities as a result of cybergogy. The most common application of ICT was for games and entertainment. It should be noted that the RTCs had only recently been set up when the study data were collected. At the time, the application of cybergogy in relation to the world of e-business was a very new concept. The next most frequent use of ICT was for social networking, such as through Facebook or Twitter. The third ranked application was using the RTC facility for surfing the web. The fourth practiced skill was in searching for specific information over the Internet, particularly regarding items linked to teaching, commerce, and work.

The four most frequently encountered ICT-related abilities of the respondents appeared to be the earliest skills acquired in mini RTCs that were previously known as Medan Info Desa (MID). Set up in 2001 to introduce ICT to the rural areas, MIDs were upgraded in 2013 and renamed mini RTCs. Cybergogy was integrated into the activities of RTCs and mini RTCs with the aim of encouraging rural residents to involve themselves in the world of e-business.

After RTCs and mini RTCs had been integrated with nine initiatives as well as various cybergogy programs, the ICT ability of the respondents in this study increased, although this rise was modest. Table 1 shows that following the intervention of cybergogy in RTCs and mini RTCs, more than $20 \%$ of the respondents were ranked between 5 to 10 whereas more than $50 \%$ had zero competency previously. Among the competencies acquired was the ability of respondents to share ideas concerning economic innovations with friends located elsewhere, and to download required information. There was an increase in the number of respondents who were involved in e-business, able to use graphic applications, and able to form a business group using WhatsApp, Facebook and Twitter. There was similarly a rise in the usage of the government's e-service facility for purposes such as the application for business licenses, the renewal of licenses, tax 
payment, and application for aid and subsidies from the government

TABLE 1. ABILITIES OF NEO-ENDOGENOUS RESPONDENTS RESULTING FROM CYBERGOGY UNDERTAKEN AT RTCS AND MiNI RTCS

\begin{tabular}{|c|c|c|c|c|c|c|}
\hline \multirow{2}{*}{ Rank } & \multirow{2}{*}{$\begin{array}{c}\text { Neo-endogenous } \\
\text { Ability }\end{array}$} & \multicolumn{5}{|c|}{ Number of Respondents } \\
\hline & & Yes & $\%$ & No & $\%$ & Total \\
\hline 1 & $\begin{array}{c}\text { Use applications for } \\
\text { entertainment and games }\end{array}$ & 355 & 63.2 & 207 & 36.8 & $\begin{array}{c}562 \\
(100 \%)\end{array}$ \\
\hline 2 & $\begin{array}{c}\text { Use applications for } \\
\text { social networking }\end{array}$ & 335 & 59.6 & 227 & 40.4 & $\begin{array}{c}562 \\
(100 \%)\end{array}$ \\
\hline 3 & Surfing the Internet & 306 & 54.4 & 256 & 45.6 & $\begin{array}{c}562 \\
(100 \%)\end{array}$ \\
\hline 4 & $\begin{array}{l}\text { Search for specific } \\
\text { information }\end{array}$ & 187 & 33.3 & 375 & 66.7 & $\begin{array}{c}562 \\
(100 \%)\end{array}$ \\
\hline 5 & $\begin{array}{l}\text { Share economic } \\
\text { innovation ideas }\end{array}$ & 176 & 31.3 & 386 & 68.7 & $\begin{array}{c}562 \\
(100 \%)\end{array}$ \\
\hline 6 & $\begin{array}{l}\text { Download required } \\
\text { information }\end{array}$ & 167 & 29.7 & 395 & 70.3 & $\begin{array}{c}562 \\
(100 \%)\end{array}$ \\
\hline 7 & $\begin{array}{l}\text { Be involved in e- } \\
\text { business }\end{array}$ & 142 & 25.3 & 420 & 74.7 & $\begin{array}{c}562 \\
(100 \%)\end{array}$ \\
\hline 8 & Use graphic content & 138 & 24.6 & 424 & 75.4 & $\begin{array}{c}562 \\
(100 \%)\end{array}$ \\
\hline 9 & Form business group & 135 & 24.0 & 427 & 76.0 & $\begin{array}{c}562 \\
(100 \%)\end{array}$ \\
\hline 10 & $\begin{array}{l}\text { Use e-services (sub of } \\
\text { e-government system) }\end{array}$ & 129 & 23.0 & 433 & 77.0 & $\begin{array}{c}562 \\
(100 \%)\end{array}$ \\
\hline
\end{tabular}

\section{CONCLUSION}

In conclusion, the Malaysian Smart Village (SV) with its telecenters, together with the introduction of cybergogy for a Multicultural Transformation approach, has set the wheels of a K-economy in motion in rural settings. Cybergogy plays a potentially critical role in enabling and empowering the rural folk with the skills and knowledge necessary to conduct ebusinesses. With rapid advancement in ICT, it is important to ensure that rural folk are not left behind in this technological era. The implementation of cybergogy at RTCs and mini RTCs would gradually but surely transform the thinking and culture of rural residents in Smart Communities, enabling them to improve themselves as well as uplift their livelihood, instead of being totally dependent on the government. Transformation has reached the stage where smart villagers can veer from the path of the P-economy that is product-based to the K-economy that is based on knowledge and services, much of which is transacted online.

\section{REFERENCES}

[1] H. A. Giroux, On critical pedagogy. London: Bloomsbury Academic, 2011.

[2] P. Freire, Pedagogy of oppressed. New York: Continuum, 2005.

[3] N. Viswanadham, Design of smart villages: India moving up the service chain. Hyderabad: Indian Business School. 2010

[4] R. Harris,"Telecentres in rural Asia: Towards a success model. Conference Proceedings of International conference on Information Technology, Communications and Development" (ITCD 2001), November 29-30, Kathmandu, Nepal, 2001

[5] M. James, Urban multiculture: Youth, politics and cultural transformation in global city. London: Pulgrave McMillan, 2015.

[6] Jabatan Perdana Menteri (JPM), Government transformation programme - The Road Map 2.0. Putrajaya, Malaysia, 2013.

[7] Malaysia Industry-Government Group for High Technology (MiGHT, JPM), Beyond innovation. Cyberjaya, Selangor: MiGHT, 2011.

[8] J.A. Malek and Z. Tahir, "Discourse the 21st Century Rural Transformation Approach, Between Sustainable and Established. The $10^{\text {th }}$ International Malaysian Studies Conference (MSC10)", Globalization and Regionalism: Malaysian in ASEAN Community Building. 15-17 August. Universiti Malaysia Sabah, 2016

[9] U. Bronfenbrenner, The ecology of human development. Massachusetts: Harvard University Press, 1979.

[10] D.G. Green, N. Klomp, G. Rimmington, and S. Sadedin, Complexity in landscape ecology, The Netherlands: Springer, 2006

[11] M.J., Wang, "Cybergogy for engaged learning. Journal of Open and Distance Education in China", 14(2), 2008, pp 14-22

[12] M.J. Wang, and J. Kang," Cybergogy of engaged learning through information and communication technology: A framework for creating learner engagement. In D. Hung \& M. S. Khine (Eds.)”, Engaged learning with emerging technologies, New York: Springer Publishing, 2006, pp. 225-253.

[13] S.I. Carrier, and L. D. Moulds, Pedagogy, andragogy, and cybergogy: exploring best-practice paradigm for online teaching and learning. Sloan-C 9th International Conference on Asynchronous Learning Networks (ALN), Orlando, USA PPT, 2003

[14] S. Hase, and C. Kanyon, (eds.), Self-determined learning: Cybergogy in action. London: Bloomsbury, 2013.

[15] L.M. Balschke, "Cybergogy and lifelong learning: A review of heutagogical practice and self-determined learning", The International Review of Research in Open and Distance Learning, Vol. 13(1), 2012, pp 56-71

[16] S. Hase, and C. Kenyon, "Moving from andragogy to cybergogy: implications for VET"', Proceedings of Research to Reality: Putting VET Research to Work: Australian Vocational Education and Training Research Association (AVETRA), Adelaide, SA, 28-30 March, AVETRA, Crows Nest, NSW, 2001. 